Does greater social diversity in schools have an impact on equity in learning outcomes?

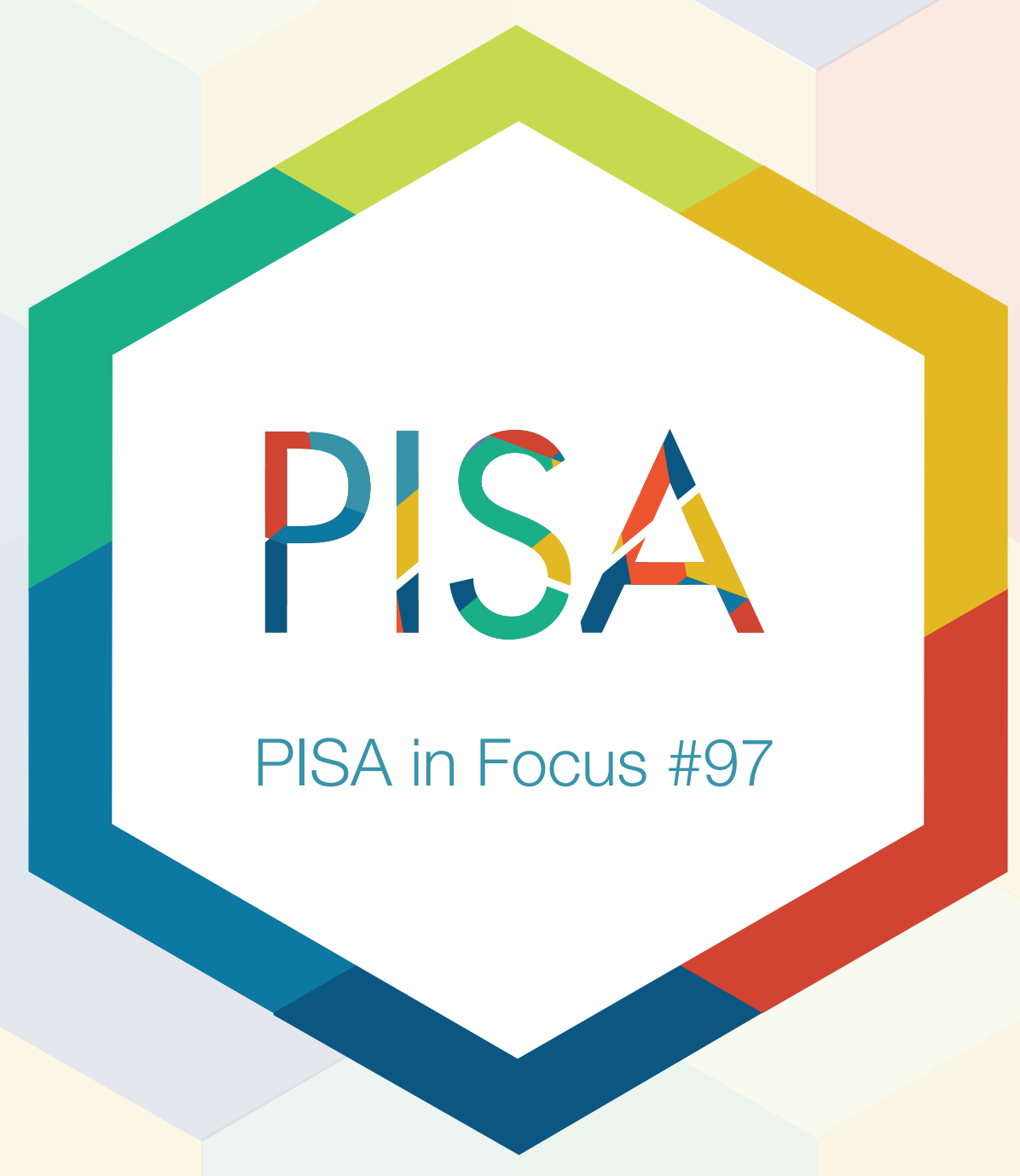




\section{Does greater social diversity in schools have an impact on equity in learning outcomes?}

- The degree of social segregation in schools varies greatly across education systems. In many Latin American countries, Beijing-Shanghai-Jiangsu-Guangdong (China) and Indonesia, students with similar backgrounds are usually concentrated in the same schools. Among OECD countries, Finland, Norway and Sweden show the least social segregation in schools.

- In many countries, schools are more likely to have high concentrations of socio-economically advantaged students than of disadvantaged students.

- School systems with higher levels of social segregation tend to offer less equitable opportunities for learning.

A student's performance in school is influenced by personal characteristics, but also, amongst other influences, by those of his or her schoolmates. Schoolmates can motivate and help each other overcome learning difficulties; but they can also disrupt instruction, require disproportionate attention from teachers, and be a source of anxiety. The way students are allocated to schools, and whether that results in greater socio-economic or academic differences across schools, may thus have an impact on education outcomes at the country level.

In which PISA-participating countries and economies are students concentrated in certain schools, depending largely on their ability or socio-economic status? How is socio-economic segregation across schools related to the achievement gaps between students of different socio-economic status?

\section{In many countries, there are more schools with high concentrations of advantaged students than of disadvantaged students}

Since PISA data include the socio-economic status of students and their schoolmates, one can determine whether students have the opportunity to learn and communicate with children from different social backgrounds, or are mostly concentrated with students similar to themselves.

The degree of social and academic diversity in schools depends on how students are allocated across schools. The social composition of a school at least partially reflects that of the area in which the school is located. In countries where families of different socio-economic status live in different neighbourhoods, students are likely to attend school with peers of similar socio-economic status.

But the socio-economic stratification of schools can also be the unintended result of other education policies. For instance, if middle-class families who live in mixed neighbourhoods choose to opt out of the local school, the students "left behind" are more likely to end up in so-called "ghetto" schools that have high concentrations of disadvantaged students. At the other extreme, if some private schools charge high tuition fees, only the most affluent families can afford to enrol their children in these "elite schools" - resulting in greater concentrations of advantaged students in some schools. 


\section{Concentration of disadvantaged/advantaged students in the same schools}

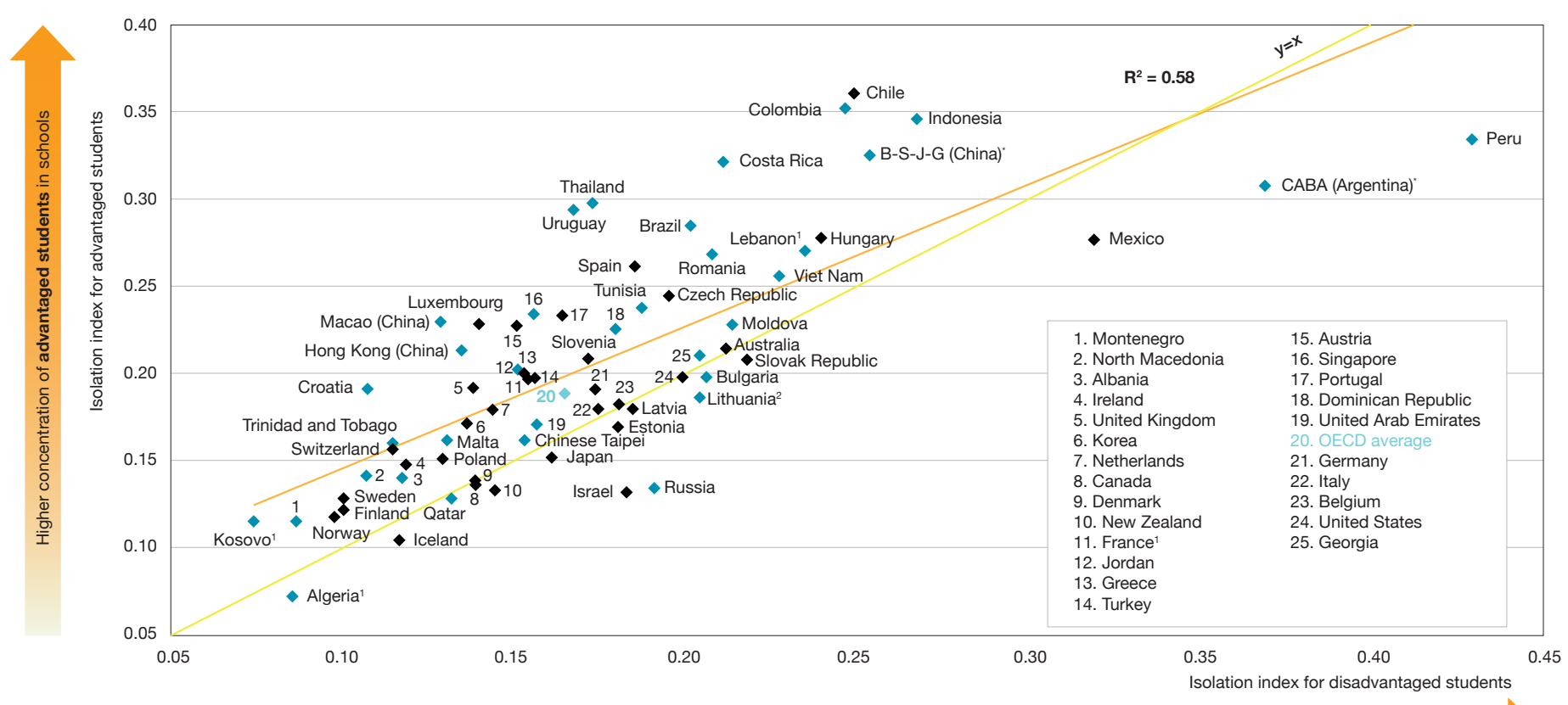

Higher concentration of disadvantaged students in schools

*B-S-J-G (China) refers to the four PISA participating China provinces: Beijing, Shanghai, Jiangsu, Guangdong. CABA (Argentina) refers to Ciudad Autónoma de Buenos Aires, Argentina. 1. In Algeria, France, Kosovo and Lebanon, the proportion of 15 -year-old students in modal grade schools is lower than $80 \%$; comparisons with other countries should be interpreted with caution. 2. Lithuania became a member of the OECD on 5 July 2018. However, consistent with other publications based on PISA 2015 data, Lithuania is not included in the OECD average.

Notes: All analyses are restricted to schools with the modal ISCED level for 15-year-old students.

Disadvantaged students are students in the bottom quarter of the PISA index of economic, social and cultural status in their own country.

Advantaged students are students in the top quarter of the PISA index of economic, social and cultural status in their own country.

The $\mathrm{R}^{2}$ value indicates the variance of the isolation of advantaged students that is accounted for by differences in the isolation of disadvantaged students across education systems. It is a measure of the strength of the relationship between the isolation of advantaged students and the isolation of disadvantaged students at the country level.

Source: OECD, PISA 2015 Database. Table 3.3 in OECD (2019), Balancing School Choice and Equity: An International Perspective Based on PISA, https://doi.org/10.1787/2592c974-en.

Amongst countries that participated in PISA in 2015, the concentration of students with similar backgrounds is especially marked in many Latin American countries. In Brazil, Chile, Colombia, Costa Rica and Uruguay, and also in Hungary, Indonesia, Lebanon, Romania, Spain, Thailand and Viet Nam, advantaged students are more likely to attend "elite schools" with high concentrations of other advantaged students than are disadvantaged students likely to attend "ghetto" schools with high concentrations of students from similarly disadvantaged backgrounds. But in Ciudad Autónoma de Buenos Aires (Argentina), Mexico and Peru, disadvantaged students are significantly more likely to be enrolled with other disadvantaged students than are advantaged students likely to be isolated in advantaged schools.

\section{But segregation related to academic achievement is more prevalent}

Results from PISA 2015 also suggest that social segregation is less prevalent than academic segregation. In many cases, social segregation across schools may, in fact, reflect the sorting of students by ability, given that achievement and socio-economic status are positively related in all countries. This may occur in school systems where students are streamed into schools that propose distinct curricula (general or vocational education) based on prior achievement. In comprehensive systems, sorting by ability may occur when parents apply to several schools and oversubscribed schools are allowed to "cream skim" the brightest students. In addition, some schools perform better than others - and thus larger shares of high performers may be the result of high school quality. 
These mechanisms are more or less pronounced, depending on the school system. For instance, in Albania, Finland, Iceland and Norway, students of different levels of ability are often enrolled in the same schools. By contrast, in Hungary and the Netherlands low achievers more often attend schools with other low achievers, while high achievers are more often with other high achievers. In some countries, such as Austria, France, Greece and Malta, there are more schools with greater concentrations of low achievers than schools with greater concentrations of high achievers. This scenario applies, although to a lesser extent, in most PISA-participating countries/economies. But in a few countries, notably Brazil, the Dominican Republic, Lebanon, Singapore and Turkey, high achievers are more likely to be clustered in a few schools than are low-achieving students.

\section{Concentration of low-/high-achieving students (in reading) in the same schools}

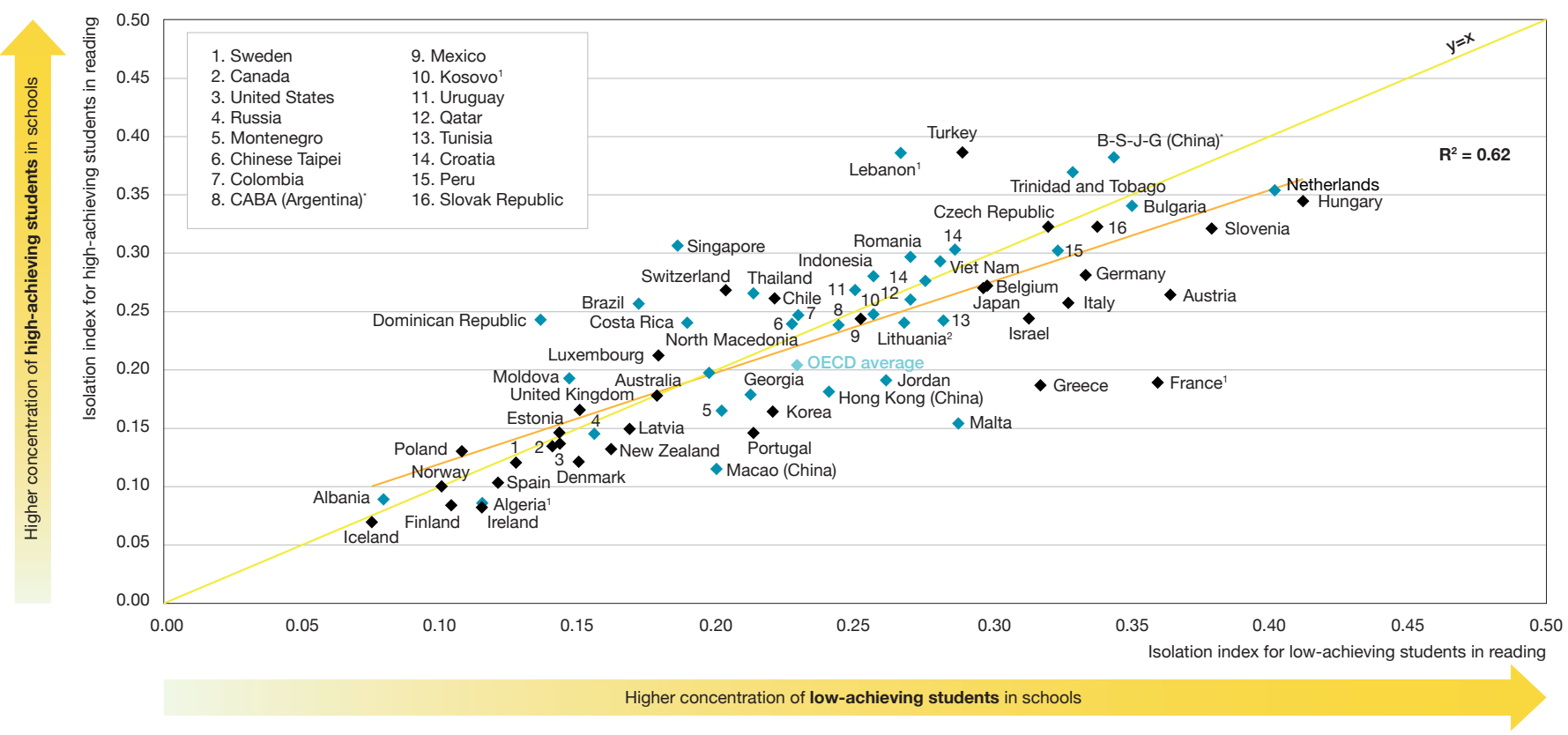

*B-S-J-G (China) refers to the four PISA participating China provinces: Beijing, Shanghai, Jiangsu, Guangdong. CABA (Argentina) refers to Ciudad Autónoma de Buenos Aires, Argentina. 1. In Algeria, France, Kosovo and Lebanon, the proportion of 15 -year-old students in modal grade schools is lower than $80 \%$; comparisons with other countries should be interpreted with caution. 2. Lithuania became a member of the OECD on 5 July 2018. However, consistent with other publications based on PISA 2015 data, Lithuania is not included in the OECD average.

Notes: All analyses are restricted to schools with the modal ISCED level for 15-year-old students.

The $\mathrm{R}^{2}$ value indicates the variance of the isolation of high-achieving students in reading that is accounted for by differences in the isolation of low-achieving students in reading across education systems. It is a measure of the strength of the relationship between the isolation of high-achieving students in reading and the isolation of low-achieving students in reading at the country level.

Source: OECD, PISA 2015 Database. Table 3.2 in OECD (2019), Balancing School Choice and Equity: An International Perspective Based on PISA, https://doi.org/10.1787/2592c974-en.

\section{Social segregation across schools has a negative impact on the equity of a country's learning outcomes}

Sorting students into schools by ability or social status may adversely affect equity in education. Disadvantaged students often struggle at school; and social and academic segregation of schools may create additional barriers to success, and reduce equity in education. For instance, disadvantaged schools may have less financial resources or may attract lessqualified teachers. Evidence has shown the detrimental impact on student performance of attending schools with many low achievers - and the benefits of having high-achieving schoolmates.

Results from PISA 2015 show that the countries where schools are less socially diverse are often those where the link between a student's performance in reading and his or her socio-economic status is the strongest. For instance, in Peru 
the level of segregation by socio-economic status across schools is high - and socio-economic status is a strong predictor of student performance in PISA. At the other extreme, in Finland, Iceland, Montenegro and Norway less than $10 \%$ of students' reading score is related to socio-economic status, while schools are, on average, more socially diverse than those in other countries and economies.

The analysis of trends in social diversity and equity over several cycles of PISA confirms this negative relationship between student sorting across schools and equity. An increase in social segregation at the country level is related to a decrease in equity in learning outcomes, even when the specifics of the school system, such as tracking policies, are taken into account.

\section{Equity in reading performance and socio-economic segregation}

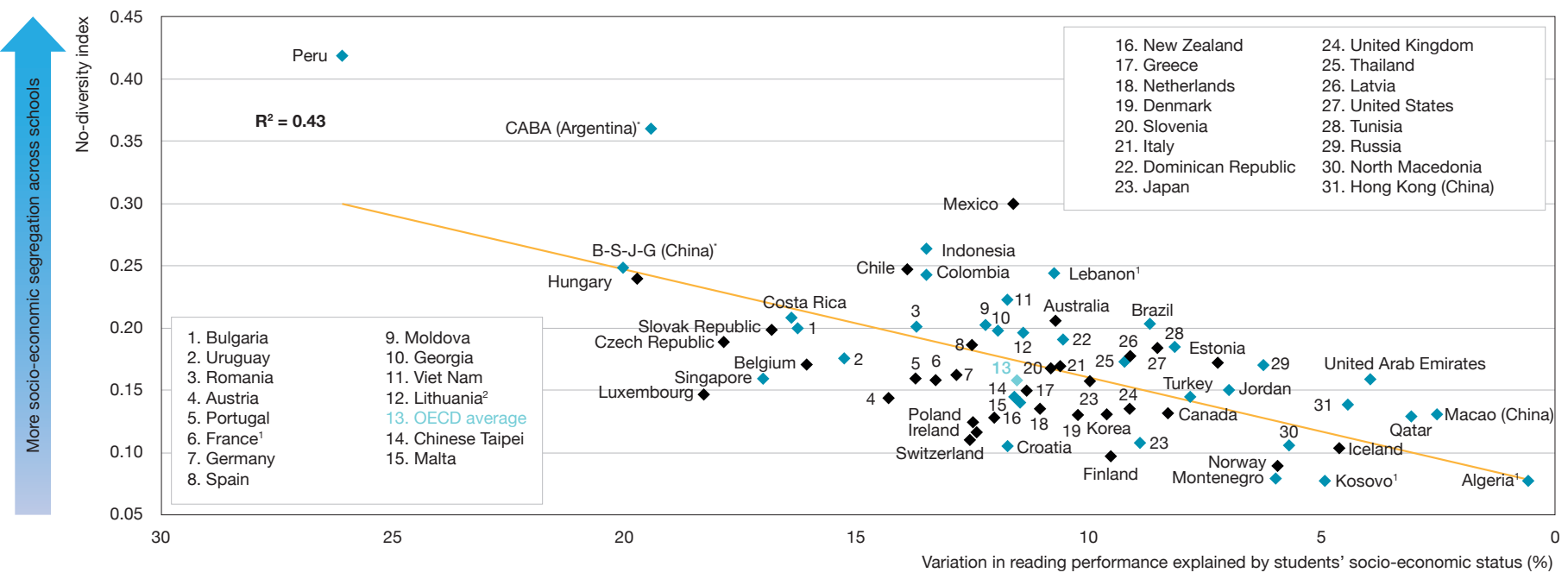

*B-S-J-G (China) refers to the four PISA participating China provinces: Beijing, Shanghai, Jiangsu, Guangdong. CABA (Argentina) refers to Ciudad Autónoma de Buenos Aires, Argentina 1. In Algeria, France, Kosovo and Lebanon, the proportion of 15-year-old students in modal grade schools is lower than $80 \%$; comparisons with other countries should be interpreted with caution. 2. Lithuania became a member of the OECD on 5 July 2018. However, consistent with other publications based on PISA 2015 data, Lithuania is not included in the OECD average. Notes: All analyses are restricted to schools with the modal ISCED level for 15-year-old students.

The no-diversity index measures whether the diversity of students observed within schools reflects the diversity of students observed at the country or economy level.

The $\mathrm{R}^{2}$ value indicates the proportion of the variance in the no-diversity index that is accounted for by differences in equity in reading performance across education systems. It is a measure of the strength of the relationship between the no-diversity index and equity in reading performance at the country level.

Source: OECD, PISA 2015 Database. Table 5.4 in OECD (2019), Balancing School Choice and Equity: An International Perspective Based on PISA, https://doi.org/10.1787/2592c974-en.

\section{The bottom line}

Students, especially disadvantaged ones, may be harmed by a lack of social and academic diversity in schools. A lack of diversity can deprive children of opportunities to learn, play and communicate with others from different social, cultural and ethnic backgrounds, threatening social cohesion. To promote equity and inclusion, the allocation of students to schools should be carefully designed in order to reduce the risk of sorting students by social status or ability. 


\section{For more information}

Contact: Pauline Givord (Pauline.Givord@oecd.org)

See: Balancing School Choice and Equity: An International Perspective Based on PISA, PISA, OECD Publishing, Paris, https://doi.org/10.1787/2592c974-en.

Coming next month: Do parents of 15-year-olds know many of their child's school friends and their families?

This paper is published under the responsibility of the Secretary-General of the OECD. The opinions expressed and the arguments employed herein do not necessarily reflect the official views of OECD member countries.

This document, as well as any data and map included herein, are without prejudice to the status of or sovereignty over any territory, to the delimitation of international frontiers and boundaries and to the name of any territory, city or area.

The statistical data for Israel are supplied by and under the responsibility of the relevant Israeli authorities. The use of such data by the OECD is without prejudice to the status of the Golan Heights, East Jerusalem and Israeli settlements in the West Bank under the terms of international law.

This work is available under the Creative Commons Attribution-NonCommercial-ShareAlike 3.0 IGO (CC BY-NC-SA 3.0 IGO). For specific information regarding the scope and terms of the licence as well as possible commercial use of this work or the use of PISA data please consult Terms and Conditions on www.oecd.org. 